\title{
A Stochastic Model on the Estimation of Time to Get Aids
}

\author{
Jaisankar $\mathbf{R}^{1}$, Saberunnisa $\mathbf{A}^{2}$ \\ Professor, Department of Statistics, Bharathiar University, Coimbatore, Tamil Nadu, India ${ }^{1}$ \\ Research Scholar, Department of Statistics, Bharathiar University, Coimbatore, Tamil Nadu, India ${ }^{2}$
}

\begin{abstract}
In HIV infection the event of significance is the time at which the condition of AIDS begins to develop in an infected individual. Nowak and May (1991) suggested the existence of Antigenic Diversity Threshold (ADT) beyond which the immune system is unable to sustain against the viral populations. It is assumed that the condition of AIDS occurs on crossing this Antigenic Diversity Threshold (ADT). In this paper an attempt has been made to estimate the time to Cross Antigenic Diversity Threshold (CADT) under the assumption that frequent contacts with infected individual has an impact on the antigenic diversity and hence on the development of AIDS.
\end{abstract}

Keywords: Human Immunodeficiency Virus, Acquired Immuno Deficiency Virus, Antigenic Diversity Threshold.

\section{INTRODUCTION}

Antigenic diversity is a major method of passively escaping the host immune observation and exhibits number of highly pathogenic microorganism. AIDS is caused by a virus called HIV which alters the immune system and make it more susceptible to infections and diseases. HIV, the causative operative of AIDS exposes lot of antigenic variety because of which the immune system finds tricky to comprehend against the antigens. The time of getting the condition of AIDS depends upon the immune capability, which frequently beaten by new targets compulsory through the antigenic diversity of the HIV invaded. It is assumed that having more and more associates with an infected person will encourage an increase in the antigenic diversity level. Several authors have intentional the different feature of antigenic diversity. According to Martin A. Nowak and Robert.M.May (1991), the infection with the Human Immunodeficiency Virus(HIV) results in severe damage to the immune system and accordingly to the condition of Acquired immunodeficiency syndrome(AIDS) after a long and changeable incubation period. An clarification has been given based on the dynamics of the interaction between immune response and antigenic dissimilarity in the virus inhabitants with the idea that AIDS outcome when the diversity of antigenic variants of HIV in an infected patient exceeds some threshold, beyond which the immune system can no longer cope. Stilianakis et al (1994) have developed a model for predicting a nonmonotonic hazard for the transition of AIDS which is partially characterized by Antigenic diversity threshold. Nowak et al. (1997) have developed an extension of Stilianakis's model with an highlight that the antigenic assortment threshold explains the long and variable interval observed between HIV disease and AIDS onset. As it is the case, the estimation of the predictable time to cross the Antigenic Diversity Threshold (ADT) plays an important role, since it provide the likely time at which the infected person expand AIDS symptoms.

In this paper, an effort has been made to estimate the time to get AIDS on the source of the antigenic diversity induced by every contact with an infected person, attractive the Antigenic Diversity Threshold (ADT) as a random patchy. It is taken that if the total antigenic diversity induced by HIV goes beyond a certain entrance level the immune system is unable to combat with the viral population, which in turn contributes to the expansion of AIDS symptoms.

\section{ASSUMPTIONS OF THE MODEL}

1. Sexual contact is the only cause of transmission of HIV.

2. Over a time period, a person is unspecified to have a number of sexual contacts with persons at casual which contain HIV infected partners.

3. Every contact with an impure supply to the augment of antigenic assortment.

4. The antigenic assortment porch of an individual is implicit to be a random variable, pursue exponential distribution.

5. The inter arrival times between consecutive contacts are unspecified to be free and identically disseminated random variables.

6. Over a period of time say $(0, t)$ an contaminated individual is contain contacts with ' $m$ ' persons at random and out of which $\mathrm{n}$ are contaminated and $\mathrm{q}$ is the probability that his casual partner is being tainted by HIV.

7. The times between any two consecutive contacts are implicit to be independent, follow exponential procedure each with parameter $\theta$. 


\section{UGC Approved Journal}

\section{NOTATIONS}

$\mathrm{X}_{\mathrm{i}} \quad$-Stochastic contribution to antigenic diversity from $\mathrm{i}^{\mathrm{th}}$ contact, and $\mathrm{X}_{\mathrm{i}}$ 's are assumed to be stochastically independent, with probability density function $\mathrm{f}($. ).

Y - A random variable representing the stochastic Antigenic diversity threshold (ADT), with probability density function $\mathrm{g}($. $)$ assumed to follow exponential Distribution with parameter $\mu$.

$\mathrm{f}^{*}($.$) \quad - Laplace transform of \mathrm{f}($.$) .$

$\mathrm{U}_{\mathrm{i}}$ - A continuous random variable denoting the inter-arrival times between successive contacts, with probability distribution function $\mathrm{W}($.$) and density function \mathrm{w}($.$) .$

$\mathrm{W}_{\mathrm{m}}($.$) - c.d.f of \sum_{\mathrm{i}=0}^{\mathrm{m}} \mathrm{U}_{\mathrm{i}}$

$\mathrm{w}^{*}($.$) \quad - Laplace transform of \mathrm{w}($.$) .$

$\mathrm{T}$ - Stochastic time at which threshold $\mathrm{Y}$ is passed.

$\mathrm{H}(\mathrm{y})$ - Probability distribution of the antigenic diversity contributed through the contacts with $\mathrm{n}$ infected individuals.

\section{THE MODEL}

The probability that the antigenic diversity developed by the $\mathrm{n}$ sexual contacts with infected individuals that does not cross the threshold level is given by,

$$
\begin{aligned}
P\left(X_{1}+X_{2}+\ldots+X_{n} \leq Y \mid Y=y\right)=\int_{0}^{\infty} H(y) & g(y) d y \\
& =\int_{0}^{\infty} H(y) \mu e^{-\mu y} d y \\
& =\mu H^{*}(\mu) \\
& =\left[\mathrm{f}^{*}(\mu)\right]^{n}
\end{aligned}
$$

Now, the probability of having m contacts during the interval $(0, t)$ is

$\mathrm{P}(\mathrm{M}=\mathrm{m} \mid \mathrm{t})=\sum_{\mathrm{m}=0}^{\infty}\left[\mathrm{W}_{\mathrm{m}}(\mathrm{t})-\mathrm{W}_{\mathrm{m}+1}(\mathrm{t})\right]$

The probability that out of ' $\mathrm{n}$ ' randomly chosen partners ' $\mathrm{m}$ ' are infected is

$$
\mathrm{P}(\mathrm{N}=\mathrm{n} \mid \mathrm{m})=\left(\begin{array}{c}
\mathrm{m} \\
\mathrm{n}
\end{array}\right) \mathrm{q}^{\mathrm{n}}(1-\mathrm{q})^{\mathrm{m}-\mathrm{n}}
$$

Then the probability that threshold has not passed at time $t$ becomes

$$
\begin{aligned}
& \mathrm{P}(\mathrm{T}>t) \quad=\sum_{\mathrm{m}=0}^{\infty}\left[\mathrm{W}_{\mathrm{m}}(\mathrm{t})-\mathrm{W}_{\mathrm{m}+1}(\mathrm{t})\right] * \sum_{\mathrm{n}=0}^{\mathrm{m}}\left(\begin{array}{c}
\mathrm{m} \\
\mathrm{n}
\end{array}\right) \mathrm{q}^{\mathrm{n}}(1-\mathrm{q})^{\mathrm{m}-\mathrm{n}} *\left[\mathrm{f}^{*}(\mu)\right]^{\mathrm{n}} \\
& =\sum_{\mathrm{m}=0}^{\infty}\left[\mathrm{W}_{\mathrm{m}}(\mathrm{t})-\mathrm{W}_{\mathrm{m}+1}(\mathrm{t})\right] *(1-\mathrm{q})^{\mathrm{m}} \sum_{\mathrm{n}=0}^{\mathrm{m}}\left(\begin{array}{c}
\mathrm{m} \\
\mathrm{n}
\end{array}\right) \mathrm{q}^{\mathrm{n}}(1-\mathrm{q})^{-\mathrm{n} *}\left[\mathrm{f}^{*}(\mu)\right]^{\mathrm{n}} \\
& =\sum_{\mathrm{m}=0}^{\infty}\left[\mathrm{W}_{\mathrm{m}}(\mathrm{t})-\mathrm{W}_{\mathrm{m}+1}(\mathrm{t})\right]^{*}(1-\mathrm{q})^{\mathrm{m}} \sum_{\mathrm{n}=0}^{\mathrm{m}}\left(\begin{array}{c}
\mathrm{m} \\
\mathrm{n}
\end{array}\right) *\left[\frac{\mathrm{f} *(\mu) \mathrm{q}}{(1-\mathrm{q})}\right]^{\mathrm{n}} \\
& =\sum_{\mathrm{m}=0}^{\infty}\left[\mathrm{W}_{\mathrm{m}}(\mathrm{t})-\mathrm{W}_{\mathrm{m}+1}(\mathrm{t})\right] *\left[1-\mathrm{q}\left(1-\mathrm{f}^{*}(\mu)\right)\right]^{\mathrm{m}} \\
& =\sum_{\mathrm{m}=0}^{\infty}\left[\mathrm{W}_{\mathrm{m}}(\mathrm{t})-\mathrm{W}_{\mathrm{m}+1}(\mathrm{t})\right]^{*} \mathrm{~A}^{\mathrm{m}},
\end{aligned}
$$

Where $A=\left[1-q\left(1-f^{*}(\mu)\right)\right]$

On simplification one can get,

$$
\begin{aligned}
& P(T>t)=1-(1-A) \sum_{m=1}^{\infty}\left[W_{m}(t)\right] A^{m-1} \text { and hence } \\
& P(T \leq t)=(1-A) \sum_{m=1}^{\infty}\left[W_{m}(t)\right] A^{m-1}
\end{aligned}
$$

Differentiating the above equation with respect to $\mathrm{t}$ and taking Laplace transform we get

$$
\begin{aligned}
l^{*}(s) & =(1-A) \sum_{m=1}^{\infty}\left[w_{m}(s)\right] A^{m-1} \\
& =(1-A) \sum_{m=1}^{\infty}\left[w^{*}(s)\right]^{m} A^{m-1} \\
& =(1-A) w^{*}(s) \sum_{m=1}^{\infty}\left[w^{*}(s)\right]^{m-1} A^{m-1} \\
& =(1-A) w^{*}(s)\left[1-w^{*}(s) A\right]^{-1} \\
& =(1-A)\left[\frac{1}{w^{*}(s)}-A\right]^{-1}
\end{aligned}
$$

Now, $\frac{d}{d s} l^{*}(s)=(1-A) \frac{d}{d s}\left[\frac{1}{w^{*}(s)}-A\right]^{-1}$

$$
=(1-A)\left[1-A w^{*}(s)\right]^{-2}\left[w^{*}(s)\right]^{-2} w^{*^{\prime}}(s)
$$


UGC Approved Journal

On substituting $A=[1-q(1-f *(\mu))]$, the expectation of $\mathrm{T}$ can be derived as,

$$
\begin{aligned}
E(T) & =\left.\frac{-d}{d s} l^{*}(s)\right|_{s=0}=-\frac{w^{*^{*}}(0)}{q\left(1-f^{*}(\mu)\right)\left[w^{*}(0)\right]^{2}} \\
E\left(T^{2}\right) & =-\left.\frac{d^{2}}{d s^{2}} l^{*}(s)\right|_{s=0} \\
& =-[1-A] \frac{d}{d s}[1-A w *(s)]^{-2} w^{*^{\prime}}(s) \\
& =-\frac{[1-A] w^{* \prime}(s)}{\left[1-A w^{*}(s)\right]^{2}}-\frac{2[1-A]\left[w^{*}(s)\right]^{2}}{\left[1-A w^{*}(s)\right]^{3}} \\
& =-\frac{\left[1-\left(1-q\left(1-f^{*}(\mu)\right)\right)\right] w^{*}(0)}{\left[1-\left(1-q\left(1-f^{*}(\mu)\right)\right) w^{*}(0)\right]^{2}}-\frac{2\left[1-\left(1-q\left(1-f^{*}(\mu)\right)\right)\right]\left[w^{*}(0)\right]^{2}}{\left[1-\left(1-q\left(1-f^{*}(\mu)\right)\right) w^{*}(0)\right]^{3}} \\
& =-\frac{1}{\left[q\left(1-f^{*}(\mu)\right]^{2}\left[w^{*}(s)\right]^{3}\right.}\left[w^{*^{*}}(s)\left(q\left(1-f^{*}(\mu)\right)\right) w^{*}(s)-2\left(w^{*^{\prime}}(s)\right)^{2}\right]
\end{aligned}
$$

And hence the variance of $\mathrm{T}$ is,

$$
\begin{aligned}
& V(T)=E\left(T^{2}\right)-[E(T)]^{2} \\
& \quad=\left[-\frac{1}{\left[q\left(1-f^{*}(\mu)\right]^{2}\left[w^{*}(s)\right]^{3}\right.}\left[w^{*^{\prime \prime}}(s)\left(q\left(1-f^{*}(\mu)\right)\right) w^{*}(s)-2\left(w^{*^{\prime}}(s)\right)^{2}\right]\right]-\left[-\frac{w^{*^{\prime}}(0)}{q\left(1-f^{*}(\mu)\right)\left[w^{*}(0)\right]^{2}}\right]^{2}
\end{aligned}
$$

In particular, if we assume that the random variable $U$ denoting inter arrival times between successive contacts follows exponential distribution with parameter ' $\theta$ ' and if the damage caused to the immune system due to a sexual contacts follows negative exponential distribution with parameter $\beta$, then $w^{*}(s)=\frac{\theta}{\theta+s}$. The mean and the variance of the time to cross the ADT can be obtained as,

$$
\begin{gathered}
E(T)=\frac{(\beta+\mu)}{\theta q \mu} \\
V(T)=\frac{(\beta+\mu)^{2}}{\theta^{2} q^{2} \mu^{2}}
\end{gathered}
$$

The behavior of the model developed is tested by simulation method and the sample mean and variance of the time to cross antigenic diversity threshold, are estimated on the basis of the random numbers generated for the distributions concerned for various combinations of parameters. The results showing the behavior of $E(T)$ and $V(T)$ are furnished in form of graphs, for different combination of the parameter values, which are given below.

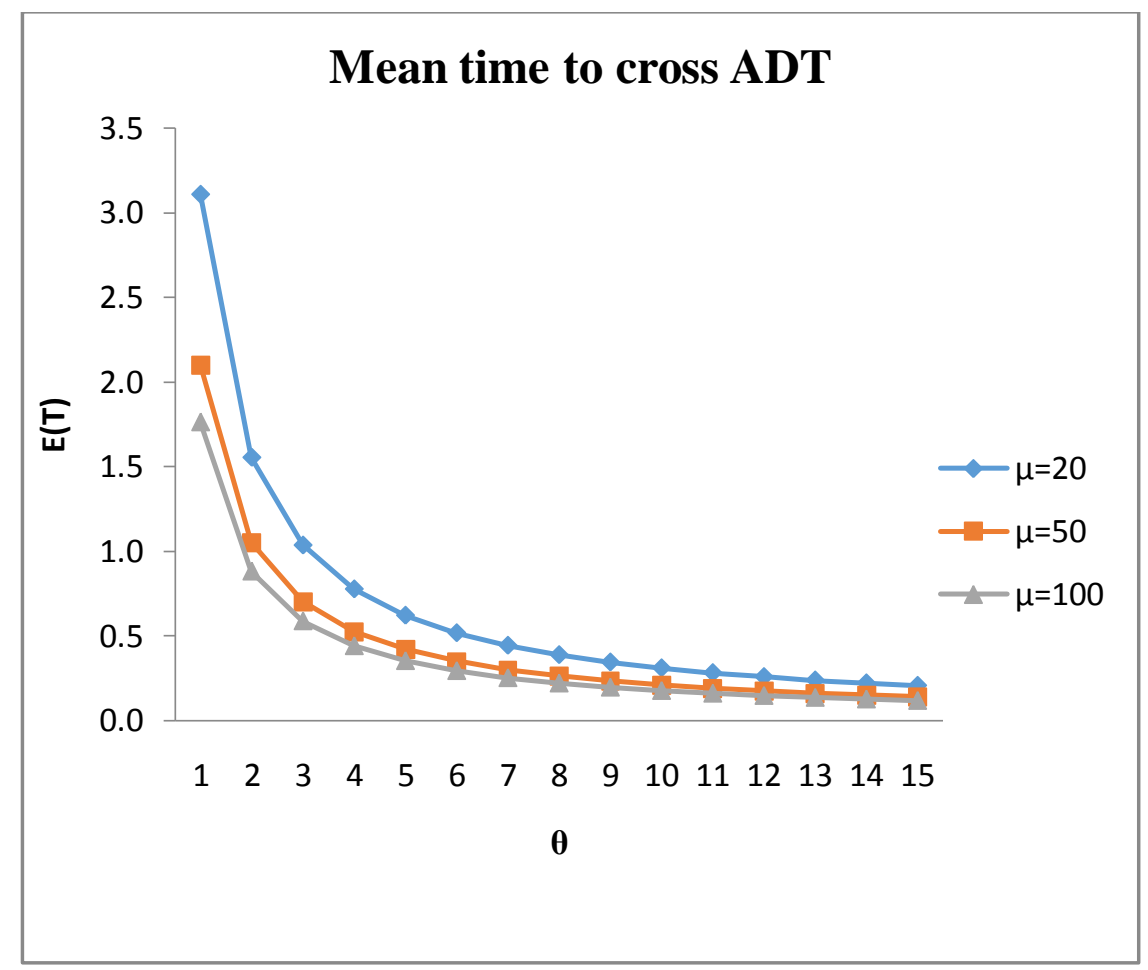

Figure 1.1 
UGC Approved Journal

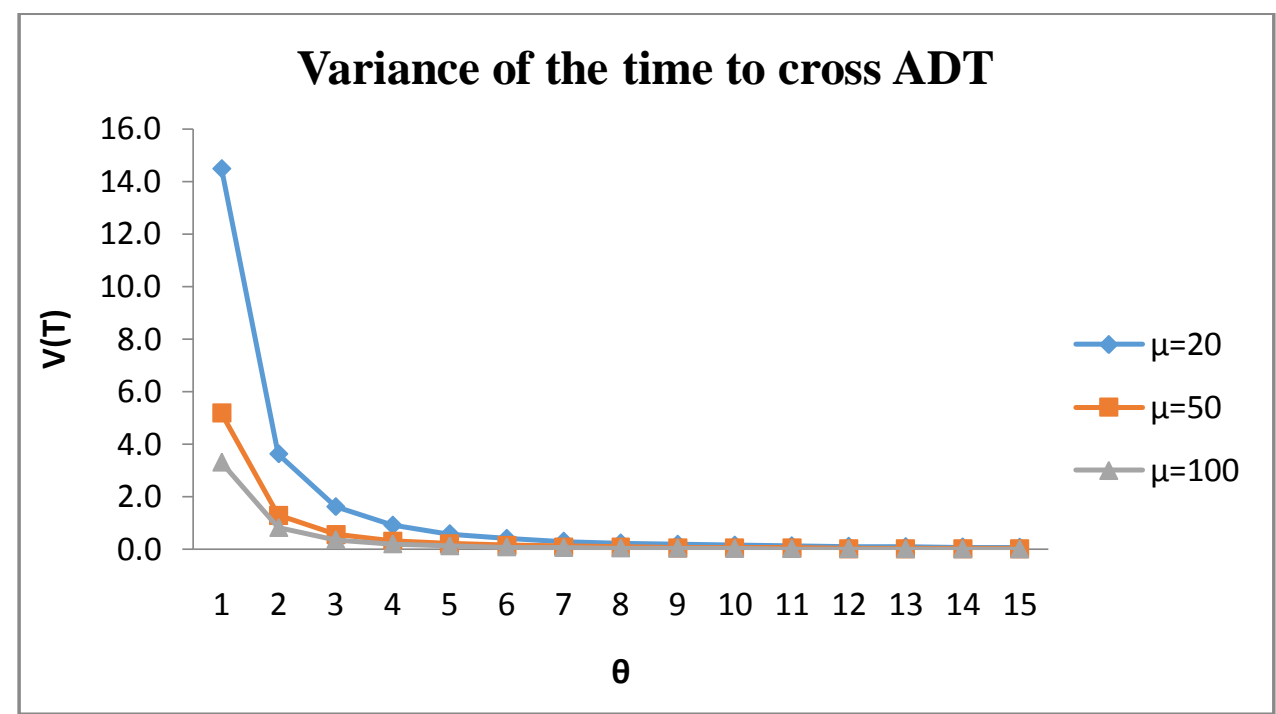

Figure 1.2

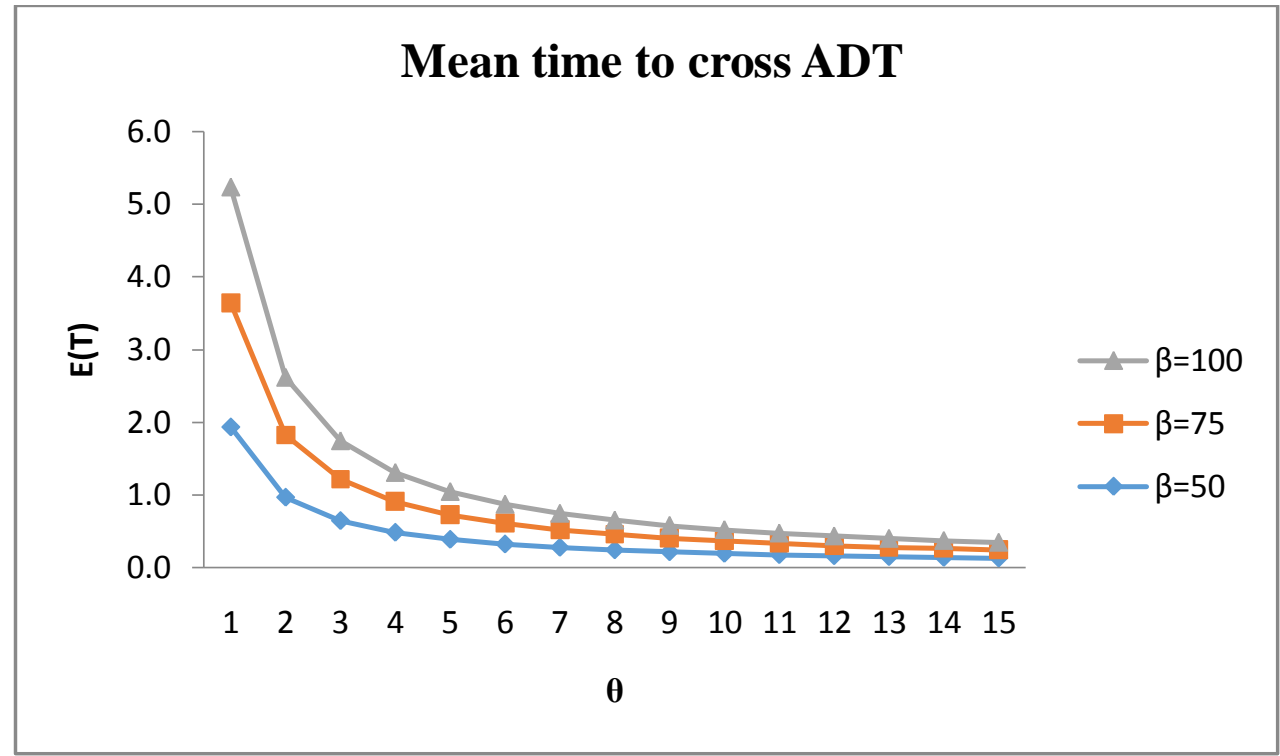

Figure 2.1

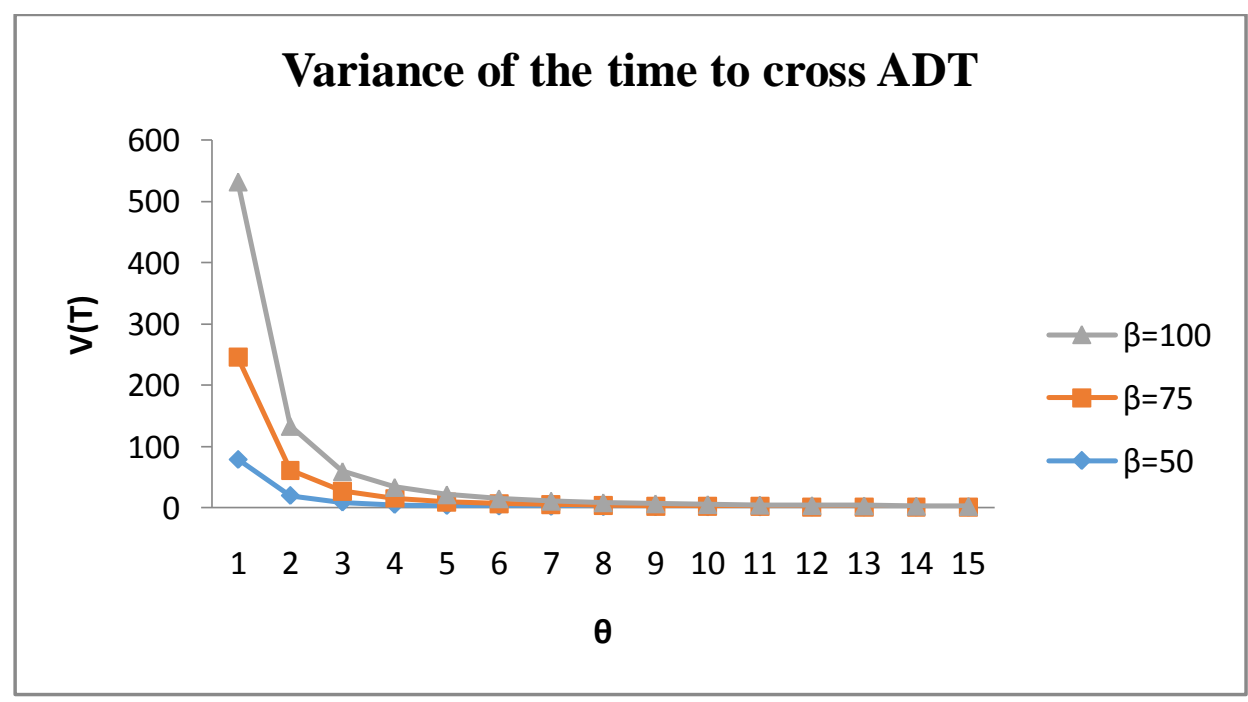

Figure 2.2 
UGC Approved Journal

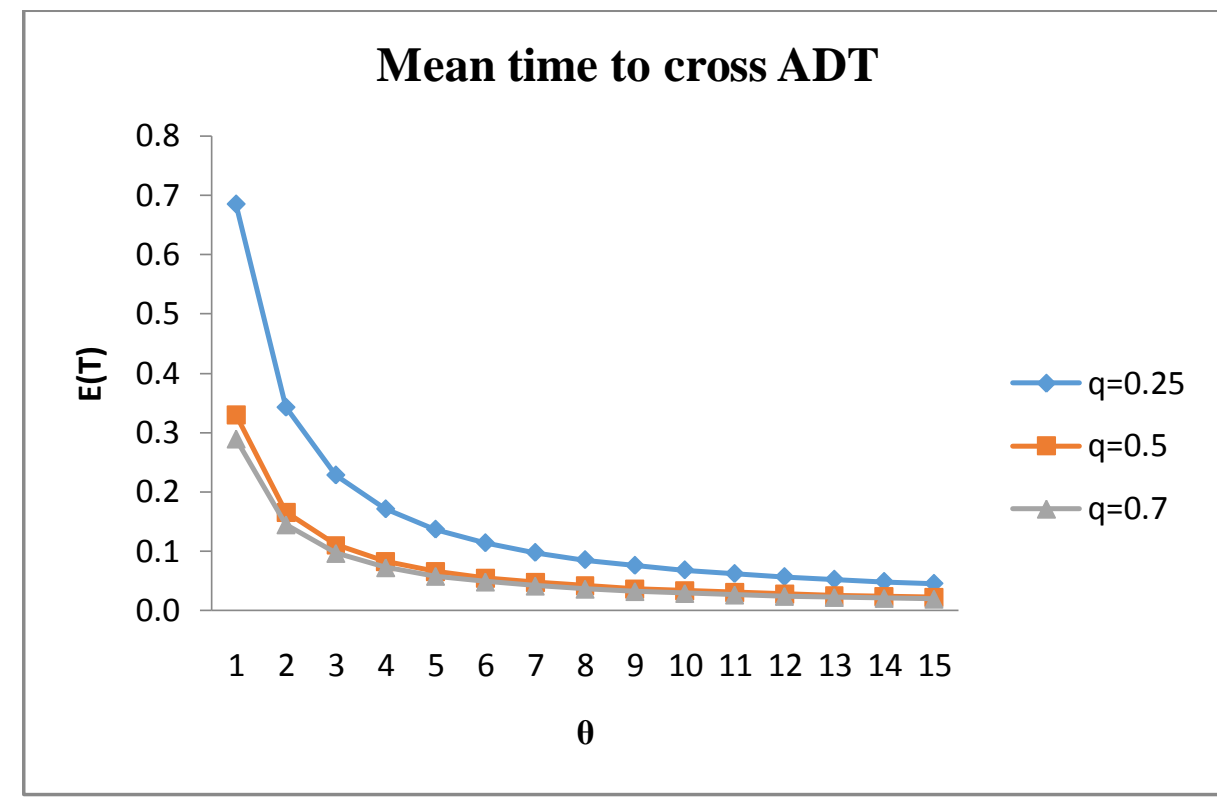

Figure 3.1

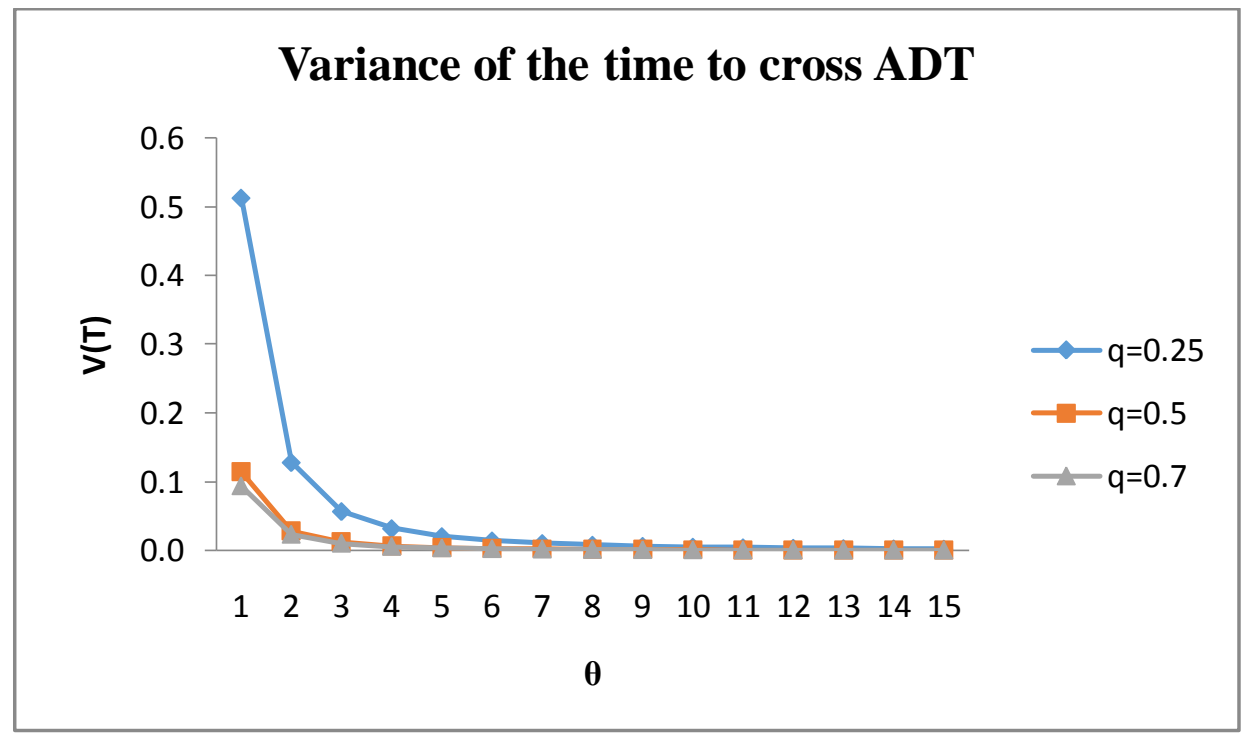

Figure 3.2

\section{CONCLUSION}

1. In fig1.1 and 1.2, the curves illustrate the expected value of $\mathrm{T}$ and the equivalent variance for dissimilar values of $\mu$ keeping $\beta$, q and $\theta$ as constants. It is observed that when $\mu$ is higher, both $\mathrm{E}(\mathrm{T})$ and $\mathrm{V}(\mathrm{T})$ are declining. This may be understand as if an infected person's ADT level is superior, then the time to get AIDS may get extended. Also it can be noticed that when the contacts are more common with infected persons the indication of AIDS will occur soon.

2. In fig 2.1 and 2.2, the performance of mean and variance of time to irritated ADT for a variety of values of $\beta$ have been pragmatic. When the $\beta$ increases the damage caused to the protected system is more. Hence it can be construe that the symptoms of AIDS may be developed soon when the resistant system gets more infected with viruses of higher antigenic diversity. Here also it is seen that if the contacts are numerous, resistant system is liable to be collapsed soon and impure person will get the AIDS symptoms earlier.

3. In figs3.1 and 3.2, the results of mean and variance of time to cross ADT is exemplified for different values of q. Here it is seen that the signify as well as the variance of time to cross the antigenic diversity threshold (ADT) increases when the value of $q$ increases. Therefore if the person has sexual contact with a group which is more susceptible for HIV infected then he will get AIDS symptoms soon. 


\section{UGC Approved Journal}

In all, it can be concluded that if an infected person is uncovered to more number of sexual contacts with other persons from a group which is more susceptible for HIV he may get the circumstance of AIDS soon. The same behavior is observed if his partner is more communicable. If an infected person has a good immune capability then the time to get AIDS may be protracted.

\section{REFERENCES}

1. Barbara Bittner et. al. (1997). 'Virus Load and Antigenic Diversity', Bulletin of Mathematical biology, Vol 59:881-896.

2. De Boer, R. J and Boerlijst, M.C. (1994). Diversity and Virulence threshold in AIDS. Applied Mathematics, Vol.94. 544-548.

3. Nowak, M.A. and May, R.M. (1991): "Mathematical Biology of HIV Infection: Antigenic Variation and Diversity threshold", Mathematical Biosciences, 106, pp. 1-21.

4. Nowak, M. A., Stekel, D. J., and May, R.M. (1997). Antigenic Diversity Thresholds and Hazard Functions. Mathematical Biosciences, Vol.139, 59-68.

5. Stillnakis, N.I., Schenzle, D and Dietz, K (1994): "On the Antigenic diversity threshold model for AIDS", Mathematical Biosciences, 121, pp. $235-247$

6. Shiboski. S.C. and N.P. Jewell (1992). Statistical analysis of the time dependence of HIV American Statist. Association, 87, 360-372. 